\title{
Gonad Protection During Paediatric Abdomen and Pelvic X-Ray Examinations
}

\author{
Kyei K. A., Antwi W. K., Nkansah O. J. \\ Department of Radiography, School of Biomedical and Allied Health Sciences, University of Ghana, Korle-Bu, Accra, Ghana
}

Email address:

adesco41@hotmail.com (K. A. Kyei), kakyei@chs.ug.edu.gh (K. A. Kyei)

\section{To cite this article:}

Kyei K. A., Antwi W. K., Nkansah O. J.. Gonad Protection During Paediatric Abdomen and Pelvic X-Ray Examinations. Clinical Medicine Research. Special Issue: Impact of Clinical Placement on Radiography Students Ghana. Vol. 4, No. 3-1, 2015, pp. 25-30.

doi: 10.11648/j.cmr.s.2015040301.16

\begin{abstract}
Background: Evidence suggests that children are more susceptible to radiation risks or hazards. In particular, their gonads are more sensitive to the effects of radiation, especially at or below reproductive age. Protecting the gonads of children and adults is of particular importance to the imaging. Aim: To investigate level of the use of gonad protection during paediatric abdomen and pelvic X-ray examinations in the Accra metropolis. Method: A quantitative, descriptive and cross sectional survey were applied where systematic random sampling was used to select five hospitals from Accra Metropolis (Ghana) that provided radiological services and had permanent radiographers. Three different tools were used in the study for data collection: observation, questionnaire and evaluation of pediatric radiographs of abdomen and pelvis. Results: A total of 44 out of 46 Radiographers recruited in five hospitals completed the questionnaire and were also involved in the observational study. The study achieved a $95.65 \%$ response rate. It was identified that $46 \%(n=20)$ of the radiographers reported they had no gonad shields in their department. Few departments (13\%) had no shields at all and $39 \%(n=17)$ of the respondents applied gonad shields only on male sexes. Although there were no laid down policies in the departments surveyed $55 \%$ of the respondents reported they were aware of policies regarding the use of gonad shields. Conclusion: It appears that there are no standardised national policies on radiation protection in general for hospitals to follow and so it is absent in the imaging departments. This has affected the availability of gonad shields and adherence to its application to protect patients. To improve quality diagnostic imaging service, there is the urgent need for management to pay serious attention to patient protection especially children against unnecessary exposure to ionising radiation during X-ray procedures. Hospital management must communicate the relevant policies and local rules concerning radiation protection in particular the use of gonad shield to protect children.
\end{abstract}

Keywords: Pediatrics Protection, Gonad Shields, Contact and Shadow Shields

\section{Introduction}

Pediatrics imaging is one of the break-through in medicine that uses X-rays for diagnosis of many health conditions in order to aid surgery and medical managements [1].

Radiography of the pelvis is commonly performed in children. Gonads in the pelvic region are particularly sensitive to the effects of radiation, especially at or below reproductive age and hence there is the need to protect the gonads by using gonad shields [2]. Kettunen[3] emphasised that children who undergo medical imaging have the possibility of developing cell mutation from X-radiation which may significantly be higher than adults.

Debate on gonad protection as a risk to the paediatric population have caught the attention of many health care professionals, especially, radiation workers, as to what should be done to minimize exposure dose [4]. The purpose of every paediatric radiographic examination is to produce high quality images, while simultaneously ensuring safety of the child, radiographer and others [5]. Children can be uncooperative and obstructive when undergoing radiographic examination and often pose challenges to the techniques and ability of the imaging staff within whose custody they have been temporarily placed.

These limitations affect almost all paediatric imaging examinations which may need repetition [6]. For this reason, paediatric radiographic examinations using gonad shields require special consideration in radiation protection. However, the use of x-rays for medical imaging can present health hazards if overexposure and inadequate protection 
requirements are not implemented or ensured. Effective radiation protection is achieved via shielding, exposure time and distance from the radiation source.

It has been observed that paediatric patients do not receive adequate protection from the effects of radiation by the nonutilization of the gonad shields. It is known that exposure to the gonads of paediatric patients to ionising radiation leads to detrimental effects such as cancer, hereditary effects or other serious disorders which are two to three times that of adults due to their greater cell proliferation rate and long life span expectation [7]. It is therefore important to perform or conduct studies on the use of gonad shields for radiation protection during diagnostic x-ray examination of paediatric abdomen and pelvis. Paediatric imaging presents problems which are best managed by specialist-trained radiographers. In particular, there is the need to ensure compliance with radiation protection regulations regarding the use of gonad shields in professional practice during pediatric abdominal and pelvic x-ray examination. The aim of the study therefore is to investigate the extent of the use of gonad shield protection during paediatric abdomen and pelvic X-ray examination in the Ghana.

\section{Methodology}

A quantitative, descriptive and cross sectional survey was found to be the most suitable method for gathering information from the study site and the respondents. The study was undertaken in five public hospitals within the Greater Accra-Metropolis to identify the extent and usage of lead gonad shields for the protection of the gonads during $\mathrm{x}$ ray examination of the abdomen and pelvis of children below the age of sixteen years January 2014 to April 2014. Radiographers (degree holders) and radiologic technicians (diploma holders) working in these selected hospitals voluntarily agreed to participate in the study were used and this was the population survey because all radiographers and radiologic technicians of the study site mentioned above were used and therefore the study did require a systematic random sampling.

Three different tools, observation, questionnaire and the evaluation of pediatric radiographs of abdomen and pelvis were used for data collection. Other options were available in the survey for data collection. Image evaluation with radiographs was used as records for the evaluation. Self administered questionnaires were given to forty-five respondents, (16) radiographers and radiologic technicians (29) working in the selected hospitals. Section A dealt with the demographic, B focused on the availability of gonad shields in their work place and the level of training regarding the use of gonad shields while Sections C and D handled their knowledge of information on available polices and guidelines and other relevant issues in connection with radiation protection of paediatrics. Direct (reactive) observations were implored for data collection which involved an on spot observation of radiographers performing abdomen and pelvic examinations to see how abdomen and pelvis were being protected during the x-ray examination. Also previous radiographs performed within the past three between were examined to ascertain shield protection of the abdomen and pelvis. Each hospital was assigned a code (the codes were used for data analysis) for anonymity and confidentiality.

Data was entered into a database and analysed statistically using the statistical package for social scientists (SPSS) version 16.0 and Microsoft Excel 2007 and were presented in the form of graphs, tables and charts for easy interpretation of results. The observational process was put into tabular form indicating whether or not gonad shields were present, quantity of the shields they had and whether or not they had gonad shields for both sexes. Two hundred radiographs, with a set target of $100 \%$ shield present to ascertain whether or not they were adequately protected and with $0 \%$ bone coverage, were examined on a daily basis each week at the studied site. The presence and absence of gonad shields in the entire abdomen and pelvic radiograph were recorded. In cases where the shields were present, the use or otherwise to protect the gonads were recorded and analysed.

Approval for the study was obtained from the research ethics committee of a higher education institution. The ethics approval was supported by written permission for the study to be conducted at the study site. All study participants gave informed consent prior to the commencement of the study.

Table 1. Number of Respondents in each Hospital and the Type of Gonad Shields Used

\begin{tabular}{llll}
\hline \multirow{2}{*}{ Study site } & Number of respondents & & Type of gonad shields used \\
\cline { 2 - 4 } & Radiographers & Radiologic Technicians & None \\
\hline KBTH & 14 & 20 & Ovarian shields \\
RH & 1 & 4 & Ovarian shields \\
LaGH & 1 & 2 & Flexible shields \\
PMLH & & 1 & None \\
LH & & 2 & None \\
\hline
\end{tabular}

Table 2. Observational Studies: Presence of Shields and the Number of Cases Observed

\begin{tabular}{|c|c|c|c|c|c|}
\hline Name of hospitals & Number of cases observed & Shields present & Quantity of shields present & Males & Females \\
\hline Korle Bu Teaching Hospital & 100 & No & - & - & - \\
\hline Ridge Hospital & 25 & Yes & 3 & 3 & - \\
\hline Legon Hospital & 25 & No & - & - & - \\
\hline La General Hospital & 25 & Yes & 4 & 4 & - \\
\hline Princess Marie Louis Hospital & 25 & Yes & 2 & 2 & - \\
\hline
\end{tabular}




\section{Results/Analysis}

A total of forty-six questionnaires (46) were distributed and Forty-four $(n=44)$ were returned giving a response rate of $95.65 \%(n=44 / 46)$. In all, Men constituted $70 \%(n=31)$ of the total population surveyed with $58.1 \%$ of them as single (unmarried). However most of the women, 53.8\%, $(n=7 / 13)$ were married. Majority of the staff surveyed, both male and female were within the age range of 29-33 $\left(n_{1}=17 / 31\right.$, for male and $\mathrm{n}_{2}=7 / 13$ for female). The majority $(86.4 \%)$ of respondents felt that their x-ray room was not child friendly. Most $61.36 \%(n=27)$ of the respondents attested to the fact that the children do not co-operate during and after x-ray examination. Gonad shields were not available to $45.5 \%$ $(n=20)$ of the radiographers.

Though it was revealed that $63.6 \% \quad(n=28)$ of the respondents had undergone special training on radiation protection, $70.5 \% \quad(n=31)$ indicated their willingness to undergo some further training on gonad protection. All of the respondents $(\mathrm{n}=44)$ had no idea on written policies concerning gonad shields, $45.5 \%(n=20)$ were however not aware of any policy regarding policy in gonad shielding.

Table 3. Number of Male and Female Abdomen / Pelvis Radiographs Examined in each Hospital

\begin{tabular}{llllll}
\hline HOSPITALS & M- AB & F-AB & M-P & F-P & TOTAL \\
\hline A & 74 & 65 & 90 & 69 & 298 \\
B & 19 & 18 & 10 & 8 & 55 \\
C & 24 & 13 & 9 & 4 & 50 \\
D & 25 & 13 & 19 & 12 & 69 \\
E & 18 & 11 & 3 & 7 & 39 \\
\hline
\end{tabular}

$\mathrm{M}-\mathrm{AB}=$ Male abdomen, $\mathrm{F}-\mathrm{AB}=$ Female abdomen, $\mathrm{M}-\mathrm{P}=$ Male pelvis, $\mathrm{F}-$ $\mathrm{P}=$ Female pelvis

Table 4. Reasons for Non Application of Gonad Shields

\begin{tabular}{lll}
\hline & Frequency & Percent \\
\hline Unwillingness for pediatrics to co-operate & 12 & 27.3 \\
Work load & 7 & 15.9 \\
Negligence & 6 & 13.6 \\
Shields not available for use & 19 & 43.2 \\
Total & 44 & 100.0 \\
\hline
\end{tabular}

Various reasons provided by respondents for the non use of gonad shields during procedures involving the abdomen and pelvis.

\section{Image Evaluation}

Radiographs taking at the accident centre, the main x-ray department and polyclinic were examined in the teaching hospital. The other four hospitals also provided radiographs from their filing rooms for examination reluctantly. Only one hospital (the Children's hospital) protected the gonads (Figure B). None of them had lead shield protection of the gonads. In one hospital the head of the X-ray department had earlier submitted that they use gonad shield however, the observation done indicated otherwise. Some of the radiographs examined are shown below.

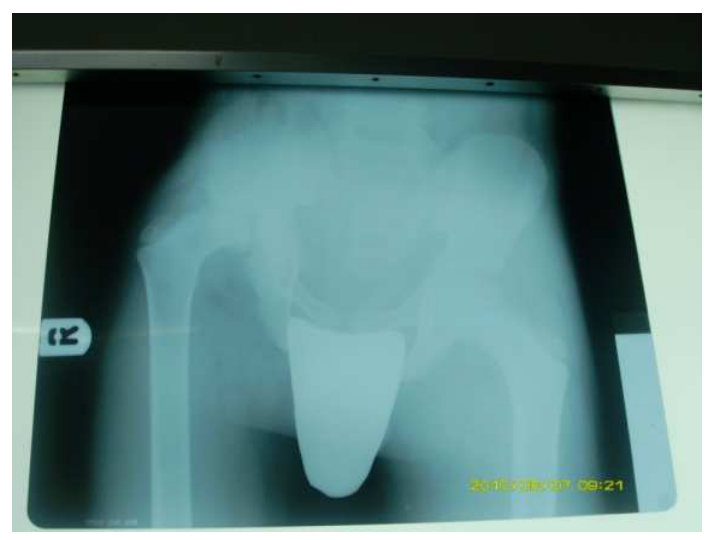

Figure A. Pelvic radiograph of a 2year old toddler without gonad shield, collimation and marker.

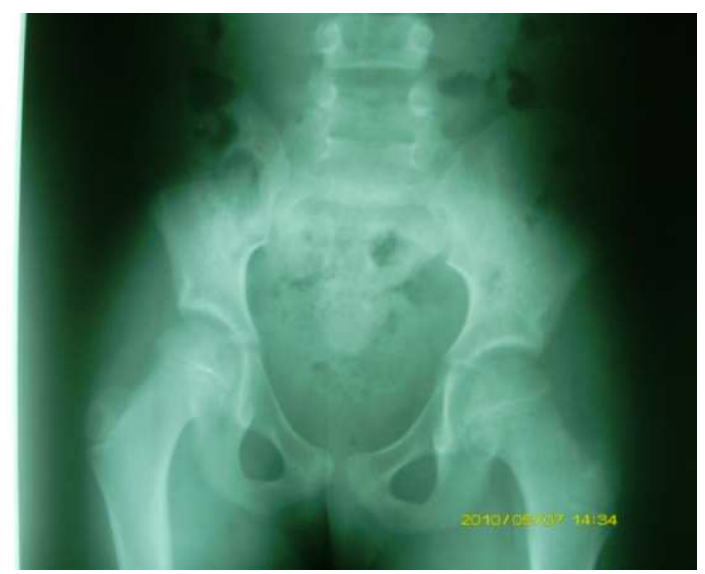

Figure B. Pelvic radiograph of a 6 year old boy showing gonad protection.

\section{Discussion}

The majority of respondents $(100 \%)(n=31 / 44)$ were males with $55 \%$ in their late twenties. The results indicated gender inequality within the profession as women were few although there are no obvious barriers in the Ghanaian society that prevents female entry into the profession. This gender in-balance could be attributed to the perception that radiation has an effect in women of child bearing age. The outcomes of the responses given by respondents $86 \%(38 / 44)$ showed that the x-ray examination rooms were not child friendly in contrast to Wilson [8] indicating that imaging rooms for children should be child friendly by stuffing with soft toys and pictures. This suggests that perhaps paediatric imaging has not been given the needed attention. It was evident from the study that almost all the departments surveyed were under resourced.

Moreover, during the observation, majority of the respondents did not establish rapport with the children. Procedures were performed in a hurried and unpleasant manner, combined with impatience in contrast with Minigh [9] recommendations. It is illustrated that more than half of 
the respondents reported that children they handled do not co-operate during and after their examination.

In contradiction to observations made, the questionnaire aspect of the study revealed that almost all respondents indicated that they reassured their paediatric patients before and after the X-rays is taken. However, it was observed that there were no interaction with the children's parents and they were not made aware of the examination so the children could sense anxiety and uncertainty in their parents. These could explain the lack of cooperation of the children during examination.

\subsection{Availability and Application Gonad Shield}

To ascertain whether or not the respondents had gonad shields in their departments, $46 \% \quad(n=20 / 44)$ of the respondents had no gonad shields in their departments implying that children being examined by them were not being protected. Although 55\% $(n=22 / 44)$ had claimed to have gonad shields, there was no evidence of the shield being used during the observational period. Social desirability could be perceived by the respondents as not telling the truth. When enquired whether or not they had gonad shields specifically for both sexes during the observation, it was seen that majority of the study sites had gonad shields for either sexes and were applied on either male or the female sex so only $27 \%(n=12 / 44)$ reported that they did not have for both sexes whiles majority $58 \%$ (26/44) said they only had for one sex (either male or female only). Again, it was reported by $13 \%$ of respondents that they do not have any shield at all. The implication of this is that in most of these departments the children would be x-rayed without protection which might increase the population dose from unnecessary radiation.

Concerning knowledge of the various types of shields, most respondents had no clue. Different descriptions were given by some respondents regarding the type of shield in the questionnaire were heart shaped type and lead skirts most of the time. During the observation, it was seen that they could not differentiate between contact and the shadow shields confusing them with lead skirts etc. Concerning the use of gonad shields on either sex, 39\% (17/44) of the participants suggested that it was often applied on the male sexes while $9 \%$ (4/44) of those who had the female shields applied it on female sexes. During the observation, it was however realized that those who apply it on either sexes had only unisex gonad shield. It was however worrying that majority of the respondents $52 \%(23 / 44)$ had no gonads shield at all for neither sex. This suggests that the radiation protection of children is being compromised in those departments.

The reason for non usage of gonad shields was diverse among the respondents. More than half of the respondents (Table 4) attributed the non usage of the shield to their non existence in the department. However, 27\% (12/44) of those that possess the shields failed to use them with the excuse of non cooperation of the children. Negligence 13.6\% (6/44) and workloads $15.9 \%(7 / 44)$ contributed to failure in using them. The observation confirmed that there were no regulations or policies enforcing them to adhere to the usage of the radiation protection devices such as gonad shields.

\subsection{Respondents Knowledge on Gonad Shields}

Majority, $86 \%(n=37 / 44)$ of the respondents (Table 5) disagreed that gonad shields were not important when one uses collimation as a form of protective measure. This depicts that they had strong foundation in the basics of radiation protection. It also depicted that $50 \%(n=22 / 44)$ of the respondents' disagreed to increasing source to image distance as increasing radiation dose to patients while the other half said otherwise. It also indicated that $93 \%(n=41 / 44)$ of the respondents agreed to gonad shield significantly reducing testicular doses to male patients. Majority of them knew how radiosensitive the testes. It showed that $96 \%$ $(n=42 / 44)$ of the respondents disagreed to source to image distance, correct exposure and shields as not being good sources to radiation protection but instead were good sources of radiation protection. It illustrates that $68 \%(n=30 / 44)$ of the respondents' disagreed that contact shields were not to be placed directly on the patient.

Table 5. Knowledge on Gonad Shielding

\begin{tabular}{lll}
\hline Statements & $\begin{array}{l}\text { Agree } \\
(\%)\end{array}$ & $\begin{array}{l}\text { Disagree } \\
(\%)\end{array}$ \\
\hline $\begin{array}{l}\text { Gonad shields are not as important as when one uses } \\
\text { collimation as a protective measure. }\end{array}$ & 13.6 & 86.4 \\
$\begin{array}{l}\text { Increasing source to image distance tends to } \\
\text { increase radiation dose to the patients } \\
\begin{array}{l}\text { Contact shields are not placed directly on the } \\
\text { patient. }\end{array}\end{array}$ & 50.0 & 50.0 \\
$\begin{array}{l}\text { Gonad shields can significantly reduce testicular } \\
\text { dose in male patients }\end{array}$ & 90.5 & 79.6 \\
$\begin{array}{l}\text { Source to image distance, correct exposure factors, } \\
\text { gonad shielding are not sources of good radiation } \\
\text { protection }\end{array}$ & 4.5 & 6.8 \\
\hline
\end{tabular}

\subsection{Training on Gonad Shields Application}

There was a contradiction to the training the respondents have had and their level of knowledge about the types and application of these shields. In particular, the study showed that $64 \%$ (28/44) of the respondents claimed to have had special training on the use of gonad shield as a radiation protection tool in practice and knowledge it appeared not to be so. The high proportion of the respondents who claimed to have had special training in the use of gonad shield did not reflect in their attitude and so could not enable them to advance the principles and practice of radiation protection. It was also worrying that, more than one third of the respondents who reported have had no training in radiation protection felt they did not even need it.

This negative attitude can be interpreted as a sign of complacency because they may have felt that those with qualification and experience do not require further training. Such attitude does not foster the principle of protection of the patient against unnecessary radiation. Perhaps lack of funds for training could be a problem, but lifelong learning is important for professions and has been suggested for radiographers/technicians [10]. That is it appears the two 
important attributes of lifelong learning (ibid), the desire to learn new things and the desire to continue learning, are lacking in these few. But overall respondents were keen to pursue further training in this area.

Although problems associated with training including lack of funding and support may be affecting the radiographic staff in the selected hospitals, it is also essential that individuals make the efforts to improve themselves since medical imaging is dynamic and new ideas and techniques keep evolving which may requires that those in the practice become abreast with current trends through constant studies

\subsection{Policies}

The study indicated that most of respondents 55\% (24/44) claimed to be aware of their department's policies concerning the use of gonad shields in radiation protection. However $46 \%$ (20/44) of the respondents were not aware of any policies regarding radiation protection in the hospitals or the country. There was total lack of written or documented policies on gonad shield or radiation protection as reported by respondents in their departments. Employers are expected to develop policies and regulations on radiation protection in diagnostic imaging for their staff but the study suggests that the policies do not exist for scrutiny. There is no evidence to suggest that all the hospitals surveyed have comprehensive radiation protection policies either, which may imply that regulations in country requiring the hospitals to be involved in radiation protection have not been effective.

\subsection{Observational Report}

In using observation, it was identified that most imaging rooms were not child friendly. The imaging rooms lacked facilities that will ease fear and anxiety in the children contrary to what was suggested by [9]. Some of the radiographers I interacted with gave the impression that gonad protections were seriously adhered to however their fellow colleagues gave a different report on the use of the lead shields. The attitude of the radiographers significantly added up to the whole ordeal as majority of them said the shields were small and could easily get lost as they were not accounted for. It was also realized that request forms submitted in some hospitals did not contain substantial clinical history to differentiate which of the cases needed gonad protection. At some hospitals where gonad protection was implemented, it was seen that the shields were not frequently applied during abdomen and pelvic x-ray examinations. In the questionnaires answered by respondents regarding the usage of gonad shields they indicated that they were using them which also contradicted what was observed. This revealed aspects of social desirability and how they felt about sharing their feelings in front of others since it was a Direct (Reactive) Observation. It was moreover noted that some departments had all types of gonad shield for both sexes but did not apply them during abdomen and pelvic examinations of paediatrics.

\section{Conclusion}

This work has provided the first evidence of the current status of gonad shield usage in paediatrics as a radiation protection tool in a representative cross-section of imaging departments in hospitals in Ghana. It has confirmed the previously unsubstantiated position that there are neither standardised ways of working in diagnostic imaging departments in Ghana, nor the necessary policies and protocols on radiation protection to enhance quality delivery of the diagnostic imaging service. There is the urgent need to give attention to radiation protection issues in the hospitals of the country.

\section{Recommendation}

Improving access to current information in order to practise good radiation protection is vital. This may include proper dissemination of any information that may be required for them in particular dose levels in the country to enable them appreciate the importance in reducing doses received by paediatric patients. Imaging departments would need to boost up workshops and seminars on radiation protection which will serve not only as a reminder to practice radiation protection but also to generate ideas that could be used to advance efficient radiation protection for dose reduction.

The hospital management should make effort to communicate the relevant policies and local rules concerning gonad shields and the enforcement agency of the legislature on radiation protection could step up their monitoring system to ensure that regulations on radiation protection are being enforced. Gonad shields as part of every pelvic and abdominal x-ray examination should include both sexes for effective protection against radiation.

Radiation protection is a public health issue so facilities for diagnostic imaging work must be sustainable for safety. It would provide an environment where radiographers and technicians can carry out their duties in a reliable space for effective radiation protection.

\section{References}

[1] Cook, J. V. (2001) Radiation Protection and Quality Assurance in Pediatrics Radiography. The British Institute of Radiology, (13):229-238

[2] Gul A, Zafar M and Maffulli N (2005) Gonadal Shields in Pelvic Radiographs in Paediatrics Patients, Bulletin of the NYU Hospital for Joint Disease.

[3] Kettunen, A (2004) Radiation Dose and Radiation Risk to the Foetus and New Borns. PP13-15.STUK-A204: Finland

[4] Abella, H. A. (2008) Radiation Dose Awareness Leads to More Paediatric Referral for Ultrasound and MRI. Diagnostic Imaging.com.

[5] Ocran, M (2008) Attitude of Radiographers in the Greater Accra Region towards Immobilization and Restraint of Paediatric Patients During X-ray Examination. School of Allied Health Sciences. 
[6] Saunder, W.B (2001) Fundamentals of Paediatric Radiology. www.answers .com/topic/paediatric. Accessed on: 28/04/14,

[7] United Nations Scientific Committee on Effects of Atomic Radiation. (2000) Sources and Effects of Ionizing Radiation. Volume 1, Report to the general assembly. New York

[8] Wilson D.J. and Allen G.M. (2010) Paediatric Imaging, children orthopaedics and fractures, pages 49-64
[9] Minigh J (2005) Peadiatric Radiation Exposure. Radiologic Technology, 76 (5): 365-375

[10] Sim J., Zadnik M.G and Radloff A (2002) Lifelong Learning in Medical Radiation Science: Stakeholders' Views. The Radiographer 49 (1): 13-17. 